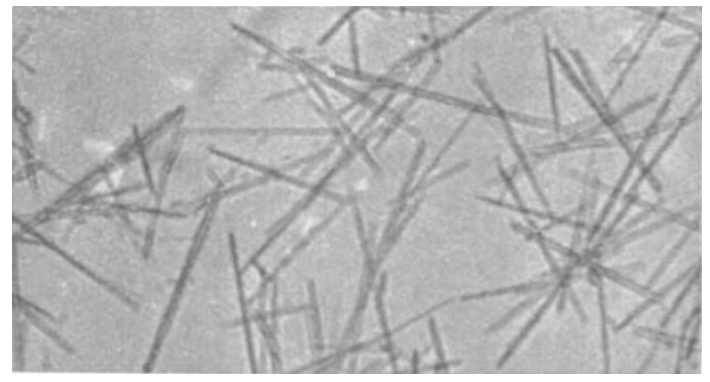

Fig. 1. Crystals of Pseudomonas cytochrome ${ }_{551}$. ( $\quad(800)$

amount of distilled water. After the re-addition of a trace of sodium dithionite, solid ammonium sulphate was added to give slight turbidity, with frequent adjustments of the $p \mathbf{H}$ to $7-8$ with ammonia. The solution gradually increased in turbidity and the needle-like crystals shown in Fig. 1 began to appear after a few hours storage. The addition of the ammonium sulphate and the storage should be carried out at almost the same temperature, since the solubility of $P$-eytochrome ${ }_{551}$ in ammonium sulphate solution increases greatly as the temperature decreases.

Twice recrystallized $P$-cytochrome ${ }_{551}$ had the absorption spectrum shown in Fig. 2, and more than two recrystallizations did not increase its purity.

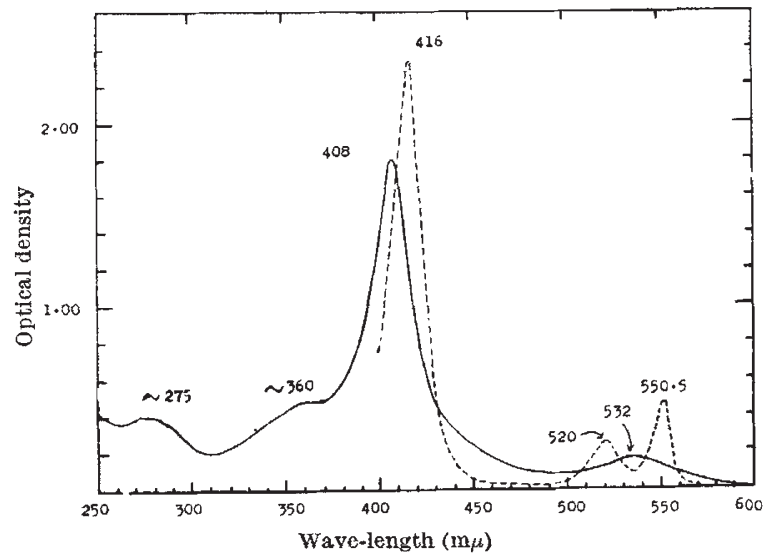

Fig. 2. Absorption spectrum of crystalline Pseudomonas cytoform. The numerals in the figure are the absorption maxima

Compared with crystalline eytochrome $c$ prepared from bovine heart muscle ${ }^{4,5}$ the $\alpha$-absorption peak was at a slightly longer wave-length (about $0.5 \mathrm{~m} \mu$ ). The twice recrystallized sample of $P$-cytochrome ${ }_{551}$ was homogeneous both by electrophoresis and by ultracentrifugal analysis.

TAKEKazu Horio

TANEaki Higashi

Masashi Nakat

KIyOShI KusaI

KazUOO OKUNUKI

Department of Biology,

Faculty of Science,

University of Osaka. Aug. 18.

1 Horio, T., J. Biochem. Japan, 45, 195 (1958).

${ }^{2}$ Horio, T., J. Biochem. Japan, 45, 267 (1958).

${ }^{3}$ Horio, T., Higashi, T., Matsubara, H., Kusai, K., Nakai, M., and Okunuki, K., Biochim. Biophys. Acta, 29, 997 (1958).

4 Hagihara, B., Morikawa, I., Sekuzu, I., Horio, T., and Okunuki, K., Nature, 178, 630 (1956).

${ }^{5}$ Yamanaka, T., Mizushima, H., Nozaki, M., Horio, T., and Okunuki, K., J. Biochem. Japan (in the press).
Action of Micrococcal Phosphodiesterase on Tobacco Mosaic Virus Nucleic Acid

Cunningham, Catlin and de Garilhe ${ }^{1}$ were the first to report the occurrence of a calcium-activated nuclease in the culture medium of Micrococcus pyogenes var. aureus. These authors partially purified the enzyme and studied its action on deoxyribonucleic acid. In the complete digest they reported the presence of mononucleoside 3 '-phosphates and also oligonucleotides. The latter were not identified except for one dinucleotide, deoxyadenylyl-(3'-5')deoxycytidine 3 '-phosphate ${ }^{2}$. Recently, it was further demonstrated that this enzyme, when activated with calcium, hydrolyses ribonucleic acid ${ }^{3}$.

This enzyme has been purified in this laboratory a hundredfold and its action on tobacco mosaic virus nucleic acid was studied. Our enzyme preparations also require calcium ion for activation. Among the reaction products formed after exhaustive digestion of tobacco mosaic virus nucleic acid with this enzyme the following mono- and di-nucleotides have so far been identified : adenosine 3 '-phosphate; guanosine 3 '-phosphate; eytidine 3 '-phosphate; uridine 3 'phosphate; adenylyl-(3'-5')-cytidine $3^{\prime}$-phosphate; adenylyl-(3'-5')-guanosine $3^{\prime}$-phosphate; uridylyl$\left(3^{\prime}-5^{\prime}\right)$-guanosine $3^{\prime}$-phosphate; and uridylyl- $\left(3^{\prime}-5^{\prime}\right)$ uridine $3^{\prime}$-phosphate; adenylyl-(3'-5')-uridine $3^{\prime}$-phosphate; and uridylyl-(3'-5')-cytidine $3^{\prime}$-phosphate. This enzyme has no action on purine or pyrimidine cyclic nucleotides, and hence the possibility of its cleavage of ribonucleic acid via transphosphorylation can be excluded. Full details of this investigation will be published elsewhere.

I wish to thank Dr. W. M. Stanley for his interest and Miss Patrice J. Driskell for supplying me with the organism used in these studies. This investigation was aided by grants from the Rockefeller Foundation and the United States Public Health Service.

\section{K. K. REDDI}

Virus Laboratory,

University of California,

Berkeley, California. Sept. 4.

${ }^{1}$ Cunningham. L., Catlin, B. W., and de Garilhe, P. M., J. Amer. Chem. Soe., 78, 4642 (1956).

2 de Garilhe, P. M., Cunningham, M., Laurila, U., and Laskowski, M., sen., J. Biol. Chem., 224, 751 (1957).

${ }^{3}$ Cunningham, L., J. Amer. Chem. Soc., 80, 2546 (1958).

\section{Isolation of $\Delta^{5,7,9}$-CEstratrienol-3-one-17 from the Urine of Pregnant Mares}

$\Delta^{5,7,8-C E S T R A T R I E N O L-3-O N E-17}$ was isolated from pregnant mares' urine in 1940 by Heard and Hoffman'. These workers obtained approximately $160 \mathrm{mgm}$. of pure material per 10,000 gallons of urine, that is, about $3.8 \mu \mathrm{gm} . / 1$., but stated that this did not represent the total quantity excreted. Since no other isolations of $\Delta^{5,7,9}$-œstratrienol-3-one-17 from pregnant mares' urine have been reported in the literature, we believe that it is of interest to record that we have found the material to be present in pregnant mares' urine in relatively large

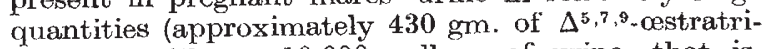
enol-3-one-17 per 10,000 gallons of urine, that is, about $10 \mathrm{mgm}$./1.) and that we have isolated the material readily in the pure state.

A concentrate, representative of mares' urine collected from approximately the fourth to ninth month of pregnancy, was prepared by methods previously outlined by us $^{2}$. The concentrate was 